\title{
Early repair of hemitruncus: Excellent early and late outcomes
}

\author{
Meena Nathan, MD, David Rimmer, MS, Gary Piercey, BS, Pedro J. del Nido, MD, John E. Mayer, MD, \\ Emile A. Bacha, MD, and Frank A. Pigula, MD
}

Objective: Anomalous origin of 1 of the branch pulmonary arteries from the aorta with 2 normal semilunar valves (hemitruncus) is a rare entity. There have been several small case series reported. We report here our single-institution surgical experience with hemitruncus from 1982 to 2006.

Methods: A retrospective case review of all cases of conotruncal anomalies at Children's Hospital Boston revealed 16 patients with hemitruncus. Ten patients had surgery in the neonatal period ( $<30$ days), 4 at 1 to 6 months, 1 at 8 months, and 1 at 2 years. Diagnosis of hemitruncus was the indication for operation in all but 1 . Fourteen of the 16 had anomalous right pulmonary artery from aorta, and 2 had left pulmonary artery from aorta. Common associated anomalies included patent foramen ovale in 14, patent ductus arteriosus in 11, and ventricular septal defect in 4 . All patients had elevated right ventricular pressures with systemic pressures in 5 and suprasystemic pressures in 9 .

Results: There was 1 operative death in this series in an infant who died from sepsis following ligation of a tracheoesophageal fistula. One patient required reoperation for supravalvar aortic stenosis and right pulmonary artery stenosis 1 year postoperatively. Three patients required 4 catheter-based interventions postoperatively. At 20 years, survival by Kaplan-Meier was 93\%; freedom from reoperation, 93\%; and freedom from catheter reintervention, $79 \%$.

Conclusions: Early repair of hemitruncus results in excellent hemodynamic and anatomic results. Survival is excellent, with a low incidence of reoperation or reintervention.

From the Children's Hospital, Boston, Harvard Medical School, Boston, Mass.

Poster Presentation at the Western Thoracic Surgical Association meeting, Sun Valley Idaho, June 21-24, 2006.

Received for publication June 19, 2006; revisions received Nov 10, 2006; accepted for publication Dec 26, 2006.

Address for reprints: Frank A. Pigula, MD, Department of Cardiac Surgery, Children's Hospital, 300, Longwood Ave, Boston, MA 02115 (E-mail: frank.pigula@ childrens. harvard.edu).

J Thorac Cardiovasc Surg 2007;133:1329-35 $0022-5223 / \$ 32.00$

Copyright $\odot 2007$ by The American Association for Thoracic Surgery

doi:10.1016/j.jtcvs.2006.12.041
A nomalous origin of 1 pulmonary artery from the ascending aorta (hemitruncus) with normal origin of the other from the right ventricle is a rare anomaly. This should be distinguished from patients with discontinuous pulmonary arteries who receive blood supply to 1 lung from a ductlike collateral associated often with tetralogy. Anomalous origin of 1 pulmonary artery from aorta was first described by Fraentzel in $1868 .{ }^{1}$ Since then, there have been several case reports and case series. The natural history of this condition is characterized by onset of severe pulmonary vascular obstructive disease (PVOD) if not corrected early. This anomaly results in a large left-to-right shunt with the entire cardiac output from the right ventricle going to 1 lung while the other lung receives blood at systemic pressure from the aorta. Often there are other additional intracardiac shunting lesions exacerbating the total hemodynamic burden. Thus the pulmonary vascular bed of both lungs may be vulnerable to the development of vascular disease. If left untreated, 1-year survival has been reported to be as low as $30 \% .^{2}$ We report our series of 16 cases, the majority of whom had surgery as neonates, with excellent short-term and long-term outcomes. 


\author{
Abbreviations and Acronyms \\ LPA $=$ left pulmonary artery \\ MPA = main pulmonary artery \\ PDA = patent ductus arteriosus \\ $\mathrm{PFO}=$ patent foramen ovale \\ PVOD $=$ pulmonary vascular obstructive disease \\ RPA = right pulmonary artery \\ TEF = tracheoesophageal fistula \\ VSD = ventricular septal defects
}

\section{Materials and Methods}

A retrospective database and chart review between 1982 and 2006 revealed 16 neonates and children who had undergone repair for anomalous origin of 1 of the branch pulmonary arteries from the aorta. This retrospective chart review was approved by the Institutional Review Board at Children's Hospital and parental consent was waived. All data were procured according to guidelines established by the committee on clinical investigation.

All patients' preoperative studies, including echocardiograms and cardiac catheterization data, were reviewed. Data obtained from the preoperative echocardiograms included: the site of origin of the anomalous pulmonary artery, presence of additional intracardiac defects, right ventricular pressures, and presence or absence of right ventricular dysfunction.

Clinical charts and databases were reviewed. Intraoperative variables of interest included: survival, procedure performed, cardiopulmonary bypass times, aortic crossclamp times, and circulatory arrest times. Postoperative variables of interest were: length of intensive care unit stay, length of hospital stay, duration of ventilatory support, surgical and catheter reinterventions, surgical complications, and length of follow-up.

Results are reported as means $\pm \mathrm{SD}$. Probabilities of survival, freedom from reoperation, and freedom from catheter reinterventions were estimated using the Kaplan-Meier method. Intercooled Stata version 8.1 (Stata Corporation, College Station, Tex) was used for statistical analysis.

\section{Results}

There were 7 boys and 9 girls. All patients were under 2 years of age at time of surgery. Ten patients were neonates (under 30 days of age), 5 patients were infants (4 patients under 6 months, 1 patient aged 8 months), and 1 patient was 2 years old. Mean weight at operation was $3.9 \pm 1.8 \mathrm{~kg}$ with a range of 2.8 to $10.5 \mathrm{~kg}$.

All patients had preoperative echocardiograms. Five patients also underwent cardiac catheterization. In 3 patients the diagnosis was missed on preoperative echocardiogram. In 2 of these 3 patients, the diagnosis was established on routine preoperative cardiac catheterization early in the series, and both had anomalous right pulmonary artery (RPA) arising from the aorta. More recently, in 1 patient the diagnosis was missed on preoperative transthoracic echocardiogram. This patient was taken to the operating room for symptoms of severe congestive heart failure attributed to
2 muscular ventricular septal defects (VSDs). The diagnosis was made when intraoperative transesophageal echocardiography could not clearly visualize the origin of the left pulmonary artery (LPA). Fourteen patients had a right anomalous pulmonary artery arising from the aorta. In 7 patients the RPA arose directly posterior from the ascending aorta, 5 had the RPA arising posterior but leftward, 1 had the RPA arising posterior and rightward, and 1 patient had the RPA arising from anterior rightward aspect of ascending aorta. Two patients had an anomalous left pulmonary artery arising from the aorta. Both arose from an anterior and leftward aspect of ascending aorta and shared a common but intact wall with the main pulmonary artery (MPA). Additional defects and surgical details are outlined in Table 1. After excision of the anomalous pulmonary artery with a rim of aortic tissue, 11 of the 16 patients had primary closure of aorta, and a pericardial patch was used to close the aortic defect in 5 patients. Thirteen patients had direct implantation of anomalous pulmonary artery onto the side of MPA; 3 patients had anterior pericardial patch augmentation of this anastomosis to maintain a tension-free anastomosis. All procedures were done under cardiopulmonary bypass. One of the 16 patients had repair performed on beating heart with no crossclamp. Seven patients had a period of circulatory arrest, all before 1991. Only 2 of these patients had an additional VSD or arch augmentation. The mean cardiopulmonary bypass time was $95 \pm 37.4$ minutes (range of 65-201 minutes), the mean aortic crossclamp time was $42 \pm 18.8$ minutes (range of 22-80 minutes), and the mean circulatory arrest time was $45 \pm 15.7$ minutes (range of 29-76 minutes). The mean time to extubation was $2.5 \pm$ 1.3 (range of 1-5 days), mean length of stay in intensive care unit was $3.8 \pm 1.4$ days (range of 3-7 days), and mean length of hospital stay was $9 \pm 2.8$ days (range of 5-17 days).

The mean length of follow-up was $7.5 \pm 6.0$ years (range of 1-17 years). There was 1 hospital death in a $2.8-\mathrm{kg}$ neonate with RPA arising from ascending aorta, tubular arch hypoplasia, large apical muscular VSD, mild hypoplasia of an unicuspid aortic valve, large patent ductus arteriosus (PDA), patent foramen ovale (PFO), right ventricular hypertrophy, and mild left ventricular hypoplasia and noncardiac anomalies (TEF). She underwent gastrostomy tube placement and external jugular Broviac (CR Bard, Murray Hill, NJ) on day of life 1 and was the taken for cardiac repair on day 5. The RPA was connected to the main pulmonary artery, the VSD was closed via a right ventriculotomy, the PFO was closed primarily, and the aortic arch was augmented with autologous fixed pericadium after PDA ligation and excision. She developed complete heart block postoperatively and underwent placement of a permanent pacemaker on postoperative day 7 , with recovery of the intrinsic conducted rhythm on postoperative day 14. Pul- 
monary complications related to the TEF preceded bacteremia, line sepsis, and death at 5 weeks of age. Autopsy revealed infected atrial and superior vena cava clot at prior line site with patent arch and RPA and MPA anastomosis.

One other patient developed postoperative seizure (patient number 5).

One of 16 patients $(6 \%)$ required reoperation for RPA occlusion and ascending aortic stenosis at 1 year after initial surgery. At initial operation, this patient had primary closure of aorta and pericardial augmentation of anterior aspect of RPA/MPA anastomosis. She then required a second bypass to augment the anterior RPA from MPA to hilum. During reoperation, the patient had interposition of an 11-mm homograft conduit between proximal MPA and distal RPA and ascending aortic enlargement with a Hemashield patch (Boston Scientific, Natick, MA). The patient also required subsequent catheter intervention for RPA dilatation and stenting.

There were 4 catheter-based interventions on 3 of 16 patients (18\%). Two of the 3 patients had pulmonary artery dilatation and stenting. One patient had balloon dilatation of the pulmonary artery. Two of these 3 patients had pericardial augmentation of the RPA to MPA anastomosis anteriorly.

Probability of freedom from death at 20 years by Kaplan-Meier estimate was $93 \%$, freedom from reoperation at 20 years was $93 \%$, and freedom from catheter reintervention at 20 years was $79 \%$ (Figure 1).

\section{Discussion}

Anomalous origin of 1 pulmonary artery (hemitruncus) is a rare congenital anomaly., This entity is anatomically distinct from discontinuous pulmonary arteries where 1 branch of the pulmonary artery is supplied by a ductlike or other major aortopulmonary collateral.

Embryologically pleuripotent neural crest cells play a role in the development of the conotruncus and ascending aorta. Origin of the left or right pulmonary artery from the aorta is the result of embyologically distinct, but related, processes. Failure of fusion of the LPA to MPA, due to the absence of the left sixth arch, results in persistence of an aortic sac from which the LPA arises. ${ }^{5}$ Anomalous origin of RPA from aorta results from a delay in or abnormal migration of the sixth right aortic arch to the left side. ${ }^{6-8}$ This entity is 4 to 8 times more common than anomalous origin of LPA from aorta. ${ }^{9}$ Anomalous origin of LPA, when it does occur, is often associated with right aortic arch. In our series, 14 of the 16 patients $(87.5 \%)$ had RPA as the anomalous pulmonary artery. DiGeorge syndrome is less common with hemitruncus anomalies as compared with other conotruncal malformations such as truncus arteriosus or interrupted aortic arch. ${ }^{10}$ In our case series we had only 2 patients (12\%) with thymic hypoplasia.
Associated anomalies include PDA, VSD, tetralogy of Fallot, interrupted aortic arch, aortopulmonary window, and isthmic hypoplasia. ${ }^{9-11}$ In our series we had only 1 patient with conoventricular VSD and PS and 1 patient with arch hypoplasia. There were no cases of interrupted aortic arch or aortopulmonary window. We had 8 patients with isolated hemitruncal lesions with no other major intracardiac or arch anomalies except for a PDA or PFO.

The pathophysiology resulting from this lesion exposes the pulmonary circulation of both lungs to pressure and volume overload. In the absence of intracardiac shunting, the entire cardiac output flows to the single lung attached to the right ventricle while the "hemitruncus" lung is exposed to unrestricted aortic blood flow and pressure. If this abnormal circulation is allowed to continue uncorrected, the early development of PVOD can be expected. ${ }^{12-14}$ In our series, 5 patients had diagnostic catheterization postoperatively. All 5 patients had systemic or suprasystemic right ventricular pressures preoperatively. Postoperatively, 3 of these patients had normalization of their right ventricular and pulmonary arterial pressures and trivial or no gradient across their anastomosis. One patient had elevated right ventricular and pulmonary arterial pressures that gradually improved with time and no gradient across anastomosis. The fifth patient had differential pulmonary vascular resistance and remained elevated on the side of the repair. Anastomotic adequacy was assured by catheterization. The child is well, and follow-up catheterization is planned.

Clinically these patients often present early in life with progressive respiratory distress and evidence of congestive heart failure. There is often a degree of cyanosis from right-to-left shunting through the PFO or PDA, secondary to elevated end diastolic pressures in a hypertensive, noncompliant right ventricle or from increased pulmonary resistance. The right ventricular pressures are elevated and may be systemic or suprasystemic. ${ }^{6,13,14}$ In our series, 14 patients had systemic or suprasystemic right ventricular pressures, and the remaining 2 patients had half systemic right ventricular pressures. Diagnosis is usually established by echocardiography, but imaging of the branch pulmonary arteries may be difficult, and cardiac catheterization is indicated when clinical failure seems out of proportion to the cardiac anatomy. More recently computed tomography angiograms and magnetic resonance imaging are being used for confirmation of suspected cases, especially in adults and older children. ${ }^{15,16}$

Early repair is the therapy of choice. Early repair avoids persistent pulmonary hypertension and the development of pulmonary vascular occlusive disease. Direct implantation was introduced by Kirkpatrick and colleagues ${ }^{17}$ in 1967 and Stanton and associates ${ }^{18}$ in 1968. Several techniques have been described in cases where direct implantation is not feasible due to length discrepancy. Van Son and Hanley ${ }^{19}$ in 1996 described anterior MPA flap anastomosis to a poste- 
TABLE 1. Patient data

\begin{tabular}{|c|c|c|c|c|c|c|c|c|c|}
\hline $\begin{array}{l}\text { Patient } \\
\text { no. }\end{array}$ & $\begin{array}{c}\text { Anomalous } \\
\text { PA }\end{array}$ & Age & $\begin{array}{c}\text { Other cardiac } \\
\text { defects }\end{array}$ & RV pressure & RV function & Procedure & Complications & $\begin{array}{l}\text { Reoperations and } \\
\text { reinterventions }\end{array}$ & Outcome \\
\hline 1 & Right & $2 y$ & $\begin{array}{l}\text { PF0, PDA (RHT } \\
\text { missed on } \\
\text { echo) }\end{array}$ & Systemic & Normal & $\begin{array}{l}\text { RHT repair, PDA } \\
\text { ligation, Lung Bx } \\
\text { (primary closure of } \\
\text { aorta, direct } \\
\text { implantation of } \\
\text { RPA) }\end{array}$ & None & None & Alive \\
\hline 3 & Right & $2 \mathrm{mo}$ & PF0, PDA & Suprasystemic & Normal & $\begin{array}{l}\text { RHT repair, PDA } \\
\text { ligation, PFO } \\
\text { closure (primary } \\
\text { closure of aorta, } \\
\text { direct implantation } \\
\text { of RPA) }\end{array}$ & None & None & Alive \\
\hline 4 & Right & $15 d$ & PF0 & Suprasystemic & Normal & $\begin{array}{l}\text { RHT repair (primary } \\
\text { closure of aorta, } \\
\text { direct implantation } \\
\text { of RPA) }\end{array}$ & None & None & Alive \\
\hline 5 & Right & $6 d$ & PFO, PDA & Suprasystemic & Normal & $\begin{array}{l}\text { RHT repair, PDA } \\
\text { ligation, (primary } \\
\text { closure of aorta, } \\
\text { direct implantation } \\
\text { of RPA) }\end{array}$ & Seizures & None & Alive \\
\hline 6 & Right & $10 \mathrm{~d}$ & PF0, PDA & Half systemic & Normal & $\begin{array}{l}\text { RHT repair, PFO } \\
\text { suture, PDA ligation } \\
\text { (primary closure } \\
\text { aorta, direct } \\
\text { implantation of } \\
\text { RPA) }\end{array}$ & None & None & Alive \\
\hline 8 & Right & $5 d$ & PF0, PDA & Suprasystemic & Depressed & $\begin{array}{l}\text { RHT repair, PFO } \\
\text { suture, PDA ligation } \\
\text { (pericardial patch } \\
\text { closure of aorta, } \\
\text { direct implant of } \\
\text { RPA) }\end{array}$ & None & None & Alive \\
\hline 9 & Right & $5 d$ & $\begin{array}{l}\text { PF0, PDA, RPA } \\
\text { origin } \\
\text { stenosis }\end{array}$ & Suprasystemic & Normal & $\begin{array}{l}\text { RHT repair, PFO } \\
\text { suture, PDA ligation } \\
\text { (primary closure } \\
\text { aorta, direct } \\
\text { implantation of } \\
\text { RPA) }\end{array}$ & None & None & Alive \\
\hline 10 & Right & $7 d$ & $\begin{array}{l}\text { PF0, mild arch } \\
\text { hypoplasia }\end{array}$ & Near systemic & Depressed & $\begin{array}{l}\text { RHT repair, PFO } \\
\text { suture, PDA ligation } \\
\text { (mod PDA intraop) } \\
\text { (primary closure of } \\
\text { aorta, direct } \\
\text { implantation of } \\
\text { RPA) }\end{array}$ & None & None & Alive \\
\hline
\end{tabular}


TABLE 1. Continued

\begin{tabular}{|c|c|c|c|c|c|c|c|c|c|}
\hline $\begin{array}{l}\text { Patient } \\
\text { no. }\end{array}$ & $\begin{array}{c}\text { Anomalous } \\
\text { PA }\end{array}$ & Age & $\begin{array}{l}\text { Other cardiac } \\
\text { defects }\end{array}$ & RV pressure & RV function & Procedure & Complications & $\begin{array}{l}\text { Reoperations and } \\
\text { reinterventions }\end{array}$ & Outcome \\
\hline 11 & Right & $8 \mathrm{~d}$ & $\begin{array}{l}\text { PFO, PDA, } \\
\text { isthmic } \\
\text { narrowing }\end{array}$ & Suprasystemic & Normal & $\begin{array}{l}\text { RHT repair, PFO } \\
\text { suture, PDA ligation } \\
\text { (primary closure of } \\
\text { aorta, anterior } \\
\text { pericardial patch } \\
\text { augmentation of } \\
\text { RPA from hilum to } \\
\text { MPA) }\end{array}$ & None & $\begin{array}{l}\text { 1. RPA and } \\
\text { ascending } \\
\text { aortic } \\
\text { reconstruction } \\
\text { at } 1 \text { year } \\
\text { postoperatively; } \\
\text { 2. RPA } \\
\text { dilatation and } \\
\text { stenting } 2 \\
\text { years } \\
\text { postoperatively }\end{array}$ & Alive \\
\hline 12 & Right & $2 \mathrm{mo}$ & $\begin{array}{l}\text { PF0, PDA, left } \\
\text { pulmonary } \\
\text { vein } \\
\text { membrane }\end{array}$ & Suprasystemic & Depressed & $\begin{array}{l}\text { RHT repair, PFO } \\
\text { closure with } \\
\text { fenestration, LPV } \\
\text { membrane } \\
\text { resection, TV } \\
\text { repair, PDA ligation } \\
\text { (pericardial patch } \\
\text { closure of aorta, } \\
\text { RPA reimplanted } \\
\text { with pericardial } \\
\text { augmentation) }\end{array}$ & None & $\begin{array}{l}\text { 1. RPA dilatation } \\
\text { and stenting } 1 \\
\text { year } \\
\text { postoperatively; } \\
\text { 2. RPA } \\
\text { dilatation 2 } \\
\text { years } \\
\text { postoperatively }\end{array}$ & Alive \\
\hline 13 & Left & $5 \mathrm{mo}$ & $\begin{array}{l}\text { Muscular VSD } \\
\text { (diagnosis } \\
\text { of HT } \\
\text { missed } \\
\text { preoperatively } \\
\text { on echo) }\end{array}$ & Half systemic & Normal & $\begin{array}{l}\text { LHT repair, muscular } \\
\text { VSD } \times 2 \text { closure } \\
\text { (primary) (primary } \\
\text { closure aorta, } \\
\text { opening of common } \\
\text { wall between LPA } \\
\text { and MPA and } \\
\text { pericardial patch of } \\
\text { LPA defect) }\end{array}$ & None & None & Alive \\
\hline 14 & Right & $9 d$ & $\begin{array}{l}\text { PFO, RAA, } \\
\text { aberrant } \\
\text { LSCA }\end{array}$ & Suprasystemic & Depressed & $\begin{array}{l}\text { RHT repair, PDA div, } \\
\text { (primary closure } \\
\text { aorta, direct } \\
\text { reimplant of RPA) }\end{array}$ & None & $\begin{array}{l}\text { RPA dilatation } 1 \\
\text { year } \\
\text { postoperatively }\end{array}$ & Alive \\
\hline 15 & Right & $2 \mathrm{mo}$ & $\begin{array}{l}\text { PFO, PDA, mild } \\
\text { AS, and Sub } \\
\text { As }\end{array}$ & Suprasystemic & Depressed & $\begin{array}{l}\text { RHT repair, PDA } \\
\text { ligation, transection } \\
\text { of aorta, direct } \\
\text { implantation of RPA } \\
\text { to MPA, pericardial } \\
\text { augmentation of } \\
\text { aortic defect and } \\
\text { EEA of transected } \\
\text { aorta }\end{array}$ & None & None & Alive \\
\hline 16 & Left & $25 d$ & $\begin{array}{l}\text { PFO, } \\
\text { conoventricular } \\
\text { VSD, PS, } \\
\text { RUPV to } \\
\text { SVC }\end{array}$ & Systemic & Normal & $\begin{array}{l}\text { LHT repair, pulmonary } \\
\text { valvuloplasty and } \\
\text { BD, VSD patch } \\
\text { (pericardial patch } \\
\text { closure of aortic } \\
\text { defect, direct } \\
\text { implant of LPA to } \\
\text { MPA by including it } \\
\text { as part of MPA } \\
\text { arteriotomy closure) }\end{array}$ & None & None & Alive \\
\hline
\end{tabular}

PFO, Patent foramen ovale; PDA, patent ductus arteriosus; $R H T$, right hemitruncus; $B x$, biopsy; RPA, right pulmonary artery; VSD, ventricular septal defect; $D C R V$, double-chambered right ventricle; $L A D$, left anterior descending artery; $R C A$, right coronary artery; $R V M B R$, right ventricular muscle bundle resection; $T E F$, tracheoesophageal fistula; $C H B$, complete heart block; $P P M$, permanent pacemaker; $M S O F$, multisystem organ failure; $T V$, tricuspid valve; $L H T$, left hemitruncus; $M P A$, main pulmonary artery; RAA, right aortic arch; $A S$, aortic stenosis; $L S C A$, left subclavian artery; $E E A$, end-to-end anastamosis.

rior aortic/branch pulmonary arterial flap. Prifty and colleagues ${ }^{20}$ in 2002 described a double surgical flap technique using a ring of aorta divided with one-third posterior flap and two-thirds anterior flap. The posterior flap was anasto- mosed to a posteriorly based trapdoor flap of MPA folded back on itself. The anterior two thirds of aortic flap were then anastomosed anteriorly to the edge of the MPA trapdoor. The entire anastomosis was performed anterior to the 


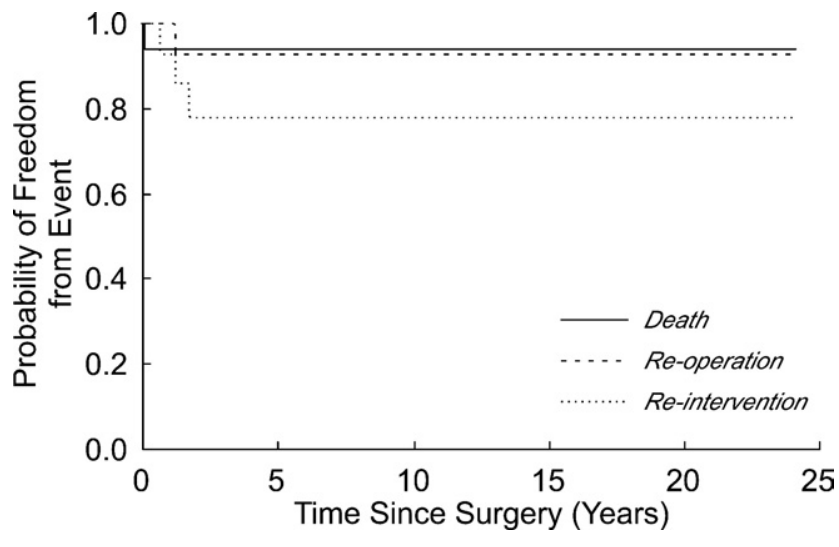

Figure 1. Kaplan-Meier curve representing probability of freedom from death, reoperation, and catheter-based reintervention at 20 years.

aorta. Other modifications of aortic/pulmonary arterial flap techniques have been described. ${ }^{21-23}$ In our series, we were successful in direct implantation of anomalous pulmonary artery into MPA in 13 of 16 patients. Only 3 patients required fixed autologous pericardial patch augmentation of the pulmonary artery implant site. Two of these 3 patients had the anomalous pulmonary artery arising from the anterolateral aspect of the aorta (RPA from right anterolateral aspect in 1 and LPA from left anterolateral aspect in the second), and therefore a greater length had to be traversed for anastomosis. One of these 2 required intervention for dilatation and stenting of the implanted pulmonary artery. The third patient developed complete occlusion of RPA requiring reoperation and homograft conduit interposition of the RPA. This homograft required later dilatation and stenting.

Hospital mortality has been reported as anywhere from $0 \%$ to $21 \%^{24-28}$ and the need for reintervention, $12.5 \%$ to $36 \% .^{24}$ Postoperative follow-up requires echocardiography and nuclear scintigraphy to diagnose acquired peripheral pulmonary stenosis. ${ }^{29}$ Catheterization can be performed as needed when indicated by these noninvasive studies. In our series, there was 1 operative death $(6 \%)$, and 3 patients required catheter-based intervention (19\%). One patient required operative intervention (6\%).

In summary, the early diagnosis and prompt surgical treatment of hemitruncus results in excellent survival and avoids development of pulmonary vascular obstructive disease. Although the frequency of reintervention is low, it is usually directed at the pulmonary artery/MPA implantation site, and a variety of techniques to complete this anastomosis have been developed. When possible, we prefer techniques that use autologous tissue in the pulmonary artery anastomosis.

\section{References}

1. Fraentzel O. Ein fall von abnormer communication der aorta mit der arteria pulmonalis. Virchows Arch Pathol Ana. 1868;43:420-6.

2. Fontana GP, Effman EL, Sabiston DC Jr. Origin of the right pulmonary artery from the ascending aorta. Ann Surg. 1987;206:102-13.

3. Jacobs JP, Quintessenza JA, Gaynor JW, Burke RP, Mavroudis C. Congenital Heart Surgery Nomenclature and Database Project: aortopulmonary window. Ann Thorac Surg. 2000;69(4 suppl):S44-9.

4. Jacobs ML. Congenital Heart Surgery Nomenclature and Database Project: truncus arteriosus. Ann Thorac Surg. 2000;69(4 suppl):S50-5.

5. Aru GM, English WP, Gaymes $\mathrm{CH}$, Heath BJ. Origin of the left pulmonary artery from the aorta: embryologic considerations. Ann Thorac Surg. 2001;71:1008-10.

6. Di Eusanio G, Mazzola A, Gregorini R, Di Manici G, Esposito GP, Procaccini B. Anomalous origin of right pulmonary artery from the ascending aorta. J Cardiovasc Surg (Torino). 1989;30:709-12.

7. Griffiths SP, Levine OR, Andersen DH. Aortic origin of the right pulmonary artery. Circulation. 1962;25:73-84.

8. Gerlis LM, Ho SY, Smith A, Anderson RH. The site of origin of nonconfluent pulmonary arteries from a common arterial trunk or from the ascending aorta: its morphological significance. Am J Cardiovasc Pathol. 1990;3:115-20.

9. Dodo H, Alejos JC, Perloff JK, Laks H, Drinkwater DC, Williams RG. Anomalous origin of the left main pulmonary artery from the ascending aorta associated with DiGeorge syndrome. Am J Cardiol. 1995; 75:1294-5

10. Takahashi K, Kido S, Hoshino K, Oqawa K, Ohashi H, Fukushima Y. Frequency of a 22q11 deletion in patients with conotruncal cardiac malformations: a prospective study. Eur J Pediatr. 1995;154:878-81.

11. Kutsche LM, Van Mierop LH. Anomalous origin of a pulmonary artery from the ascending aorta: associated anomalies and pathogenesis. Am J Cardiol. 1988;61:850-6.

12. Yamaki S, Suzuki Y, Ishizawa E, Kaqawa Y, Horiuchi T, Sato T Isolated aortic origin of right pulmonary artery. Report of a case with special reference to pulmonary vascular disease in the left and right lungs. Chest. 1983;83:575-8.

13. Keane JF, Maltz D, Bernhard WF, Corwin RD, Nadas AS. Anomalous origin of one pulmonary artery from the ascending aorta. Diagnostic. physiological and surgical considerations. Circulation. 1974;50:58894.

14. Fong LV, Anderson RH, Siewers RD, Trento A, Park SC. Anomalous origin of one pulmonary artery from the ascending aorta: a review of echocardiographic, catheter, and morphological features. Br Heart J. 1989;62:389-95.

15. Rosa U, Wade KC. CT findings in hemitruncus. J Comput Assist Tomogr. 1987;11:698-700.

16. Sechtem U, Jungehulsing M, de Vivie R, Mennicken U, Hopp HW. Left hemitruncus in adulthood: diagnostic role of magnetic resonance imaging. Eur Heart J. 1991;12:1040-4.

17. Kirkpatrick SE, Girod DA, King H. Aortic origin of the right pulmonary artery. Surgical repair without a graft. Circulation. 1967;36: 777-82.

18. Stanton RE, Durnin RE, Fyler DC, Lindesmith GG, Meyer BW. Right pulmonary artery originating from ascending aorta. Am J Dis Child. 1968;115:403-13.

19. van Son JA, Hanley FL. Use of autogenous aortic and main pulmonary artery flaps for repair of anomalous origin of the right pulmonary artery from the ascending aorta. J Thorac Cardiovasc Surg. 1996;111: 675-6.

20. Prifti E, Frati G, Crucaen A, Vanini V. A modified technique for repair of the anomalous origin of the right pulmonary artery from the ascending aorta. Eur J Cardiothorac Surg. 2002;22:148-50.

21. McMurtry K, Srivastava S, Nguyen KH. Description of a new technique for reimplanting the anomalous right pulmonary artery. Ann Thorac Surg. 2003;76:628-30.

22. Guadalupi P, Spadoni I, Vanini V. Repair of hemitruncus with autologous arterial ring and valved bioconduit. Ann Thorac Surg. 2000;70: 1708-10.

23. Prifti E, Bonacchi M, Vanini V, Bartolozzi F. Double-flap technique for repair of anomalous origin of right pulmonary artery from ascending aorta. Ann Thorac Surg. 2004;78:1883-4. 
24. Peng EW, Shanmugam G, Macarthur KJ, Pollock JC. Ascending aortic origin of a branch pulmonary artery - surgical management and longterm outcome. Eur J Cardiothorac Surg. 2004;26:762-6.

25. Prifti E, Crucean A, Bonacchi M, Bernabei M, Leacche M, Murzi B, et al. Postoperative outcome in patients with anomalous origin of one pulmonary artery branch from the aorta. Eur J Cardiothorac Surg. 2003;24:21-7.

26. Prifti E, Bonacchi M, Murzi B, Crucean A, Bernabei M, Luisi VS, et al. Anomalous origin of the left pulmonary artery from the aorta. Our experience and literature review. Heart Vessels. 2003;18:79-84.
27. Prifti E, Bonacchi M, Murzi B, Crucean A, Leacche M, Bernabei M, et al. Anomalous origin of the right pulmonary artery from the ascending aorta. J Card Surg. 2004;19:103-12.

28. Abu-Sulaiman RM, Hashmi A, McCrindle BW, Williams WG, Freedom RM. Anomalous origin of one pulmonary artery from the ascending aorta: 36 years' experience from one centre. Cardiol Young. 1998;8:449-54.

29. Kinney JB Jr, Schofield TD, Kawabori I, Budd SE, Bauman JM. Quantitative perfusion imaging assessing acquired discrete peripheral pulmonary artery stenosis. J Nucl Med. 1993;34:1995-7. 